\title{
Sarcomatoid lung cancer (spindle/giant cells): An aggressive disease?
}

Nicolas Venissac, $\mathrm{MD}^{\mathrm{a}}$, Daniel Pop, $\mathrm{MD}^{\mathrm{a}}$, Sandra Lassalle, $\mathrm{MD}^{\mathrm{b}}$, Frederic Berthier, $\mathrm{MD}^{\mathrm{c}}$, Paul Hofman, MD, $\mathrm{PhD}{ }^{\mathrm{b}}$, and Jérôme Mouroux, MD, $\mathrm{PhD}^{\mathrm{a}}$

From the Departments of Thoracic Surgery $^{\mathrm{a}}$ and Clinical and Experimental $\mathrm{Pa}$ thology, ${ }^{\mathrm{b}}$ Pasteur Hospital, Nice, France; and the Department of Medical Informatics and Information, Cimiez Hospital, ${ }^{\mathrm{c}}$ Nice, France.

Received for publication Jan 27, 2007; revisions received May 7, 2007; accepted for publication May 11, 2007.

Address for reprints: Daniel Pop, MD, Thoracic Surgery Department, Pasteur Hospital-Building H1, 30 Avenue de la Voie Romaine, 06002 Nice, France (E-mail: danielpopch@yahoo.com).

J Thorac Cardiovasc Surg 2007;134:619-23

0022-5223/\$32.00

Copyright (C) 2007 by The American Association for Thoracic Surgery

doi:10.1016/j.jtcvs.2007.05.031
Objective: We investigated the clinical, surgical, and pathologic features of sarcomatoid lung carcinomas with spindle/giant cells, giving special attention to the prognostic behavior of these rare tumors.

Methods: Surgical specimens from 39 patients (29 men and 10 women; mean age, 61 years) were examined by means of light microscopy. Preoperative and postoperative data were collected, and survival was calculated by using the Kaplan-Meier method.

Results: Nineteen patients were diagnosed with cancer preoperatively. Only one sarcomatoid tumor had been diagnosed. Presenting symptoms were noted in $85 \%$ of patients, and complete resection was achieved in 37 tumors. Postoperative pTNM staging: T2/T3/T4, 22/15/2; N0/N1/N2, 28/8/3; 15 stage IB, 14 stage IIB, 7 stage IIIA, 2 stage IIIB, and 1 stage IV. Histopathologic analysis revealed necrosis in $90 \%$ of the tumors (34 pleomorphic, 3 spindle cell, and 2 giant cell carcinomas). During follow-up (median, 24 months), 21 patients died of disease recurrence, and 3 died of postoperative complications. The 5-year survival rate (33\%; median, 11 months) was negatively influenced by large tumors $(7.5 \%$ survival for $\geq 7 \mathrm{~cm}$ vs $56 \%$ for $<7$ $\mathrm{cm}, P=.0026)$. The disease-free interval was significant for patients who relapsed ( $0 \%$ for disease-free interval $<6$ months vs $33 \%$ for disease-free interval $\geq 6$ months, $P=.0019$ ).

Conclusions: A highly heterogeneous group, spindle/giant cell lung carcinomas tend to be symptomatic, peripheral, and necrotic. Preoperative diagnosis is difficult. Most patients in our study relapsed and died the first year after surgical intervention. Surgical intervention can permit long-term survival, but adjuvant therapy warrants consideration because of the aggressive nature of these tumors.

$\mathrm{P}$ rimary lung cancer, a major public health problem in France, is the first cause of death from cancer in men $(23.5 \%)$ and the third cause in women $(6.4 \%)$ after breast and colorectal cancer. ${ }^{1}$ An estimated 28,000 new cases occurred in 2000. The 5-year survival rate, all stages considered together, remains a low $13 \%$ in men and $16 \%$ in women. ${ }^{2}$

During the last 2 decades, the histologic classification of lung cancer has evolved $^{3-5}$ thanks to progress in histologic and immunohistochemical techniques and molecular biology. One newly defined entity is a heterogeneous group of non-small cell lung carcinomas (NSCLCs) referred to as "carcinomas with pleomorphic, sarcomatoid, or sarcomatous elements" that contain a sarcoma or sarcomalike component. ${ }^{4}$ Three groups are currently recognized: carcinomas with spindle cells, giant cells, or both; carcinosarcomas; and pulmonary blastomas. Histopathologically, carcinomas with spindle cells, giant cells, or both are subdivided into 3 groups: (1) pleomorphic carcinoma, an NSCLC containing at least $10 \%$ spindle cells, giant cells, or both or a carcinoma consisting of both spindle and giant cells; 


$$
\begin{aligned}
& \text { Abbreviations and Acronyms } \\
& \begin{aligned}
\mathrm{CT} & =\text { computed tomography } \\
\mathrm{DFI} & =\text { disease-free interval } \\
\text { FDG-PET }= & \text { fluorodeoxyglucose positron emission } \\
& \text { tomography } \\
\text { GCC } & \text { giant cell carcinoma } \\
\text { NSCLC }= & \text { non-small cell lung carcinoma } \\
\text { SCSGC }= & \text { sarcomatoid carcinoma with spindle cells, } \\
& \text { giant cells, or both } \\
\text { SSC } & \text { spindle cell carcinoma } \\
\text { WHO } & \text { World Health Organization }
\end{aligned}
\end{aligned}
$$

(2) spindle cell carcinoma (SCC) containing only spindle cells; and (3) giant cell carcinoma (GCC) containing only giant cells. These tumors feature a high mitotic count, and large zones of necrosis are commonly encountered. ${ }^{4}$ Antibodies against epithelial markers, such as cytokeratins and epithelial membrane antigen or, more recently, monoclonal antibodies, are helpful in establishing the diagnosis. ${ }^{6}$

Several studies have investigated the histologic features of these tumors, ${ }^{6-12}$ but they are all retrospective and cover only small numbers of patients. Little research has been conducted on these tumors' clinical, therapeutic, and prognostic aspects. ${ }^{13-16}$

This study reports our findings concerning the clinical, surgical, and pathologic features of these tumors and analyses the outcome of sarcomatoid carcinomas with spindle cells, giant cells, or both (SCSGCs).

\section{Materials and Methods}

From January 1, 1991, to May 31, 2006, all patients with SCSGCs seen in our department who underwent anatomic resection and systematic lymph node dissection (interlobar, hilar, and mediastinal nodes) were included in the study. All pleomorphic carcinomas, pure SSCs, and pure GCCs were included. Carcinosarcomas and pulmonary blastomas were excluded, as were specimens obtained by means of atypical resections or other surgical biopsies. All tumor samples were reinterpreted by the same pathologist (S. Lassalle). All of the tumors satisfied the criteria of the latest international 2004 World Health Organization (WHO) classification. $^{5}$ Demographic data, clinical symptoms, and preoperative assessment data were recorded for all patients. The pretherapy work-up systematically included chest radiography, fiberoptic bronchoscopy, and chest computed tomography (CT) with contrast enhancement. Abdominal and brain CT scans, a bone scan, and, starting in 2003, an F-18 fluorodeoxyglucose positron emission tomographic (FDG-PET) scan completed the assessment. When necessary, diagnosis, staging, or both was supplemented by transparietal fine-needle biopsy and video-assisted mediastinoscopy. Clinical disease staging was performed according to the 1997 International TNM staging system. ${ }^{17}$ The operative techniques, types of resection, postoperative complications, and hospital stay were recorded, as was use of complementary therapy (chemotherapy, radiotherapy, or both). The histologic features of
Table 1. Patient characteristics

\begin{tabular}{llr}
\hline & \multicolumn{1}{c}{ Patients } \\
\hline Sex & Male & $29(74 \%)$ \\
Symptoms & Female & $10(26 \%)$ \\
Location & Yes & $33(85 \%)$ \\
& No & $6(15 \%)$ \\
Size & Left & $15(38 \%)$ \\
Histology & Right & $24(62 \%)$ \\
& $\geq 7$ cm & $19(49 \%)$ \\
& $<7$ cm & $20(51 \%)$ \\
pT & Pleomorphic & $34(87 \%)$ \\
& Pure spindle cells & $2(5 \%)$ \\
& Pure giant cells & $3(8 \%)$ \\
pN & T2 & $22(56 \%)$ \\
& T3 & $15(39 \%)$ \\
& T4 & $2(5 \%)$ \\
Stage & N0 & $28(72 \%)$ \\
& N1 & $8(20 \%)$ \\
& N2 & $3(8 \%)$ \\
& IB & $15(39 \%)$ \\
& IIB & $14(36 \%)$ \\
& IIIA & $7(17 \%)$ \\
& IIIB & $2(5 \%)$ \\
& IV & $1(3 \%)$ \\
\hline
\end{tabular}

the tumors (size, location, necrosis, blood vessel invasion, and pTNM) were also noted.

Follow-up was complete for all patients, and their status was known as of June 15, 2006. Any relapse (local or distant), the disease-free interval (DFI; time between surgical intervention and relapse), and the duration of patient survival were noted. The probability of survival and the various prognostic factors were calculated according to the Kaplan-Meier method for univariate analysis and the Cox proportional hazards model for multivariate analysis. Statistical analysis was carried out with SPSS software (SPSS, Inc, Chicago, Ill).

\section{Results}

Thirty-nine patients met the selection criteria, and the mean age was 61 years (range, 39-84 years). The patient's characteristics are listed in the Table 1 . Chest radiographs revealed an excavating lesion in $6(15 \%)$ patients, and CT scanning demonstrated signs of necrosis in $27(69 \%)$ patients. Nineteen patients had a preoperative diagnosis of lung cancer, and only 1 was positive for sarcomatoid cancer. Fourteen patients had an F-18 FDG-PET scan: all tumors showed intense enhancement (standardized uptake value range, 16-26).

Resections consisted of pneumonectomy in 7 cases (1 complete), bilobectomy in 3 cases, and lobectomy in 29 cases. Associated procedures included 2 wedge resections (trans-fissural tumors), 6 parietal resections, and 1 diaphragmatic resection extending to the atrium. A complete R0 resection was achieved in 37 (95\%) patients; 2 patients had residual (R1) disease microscopically. 


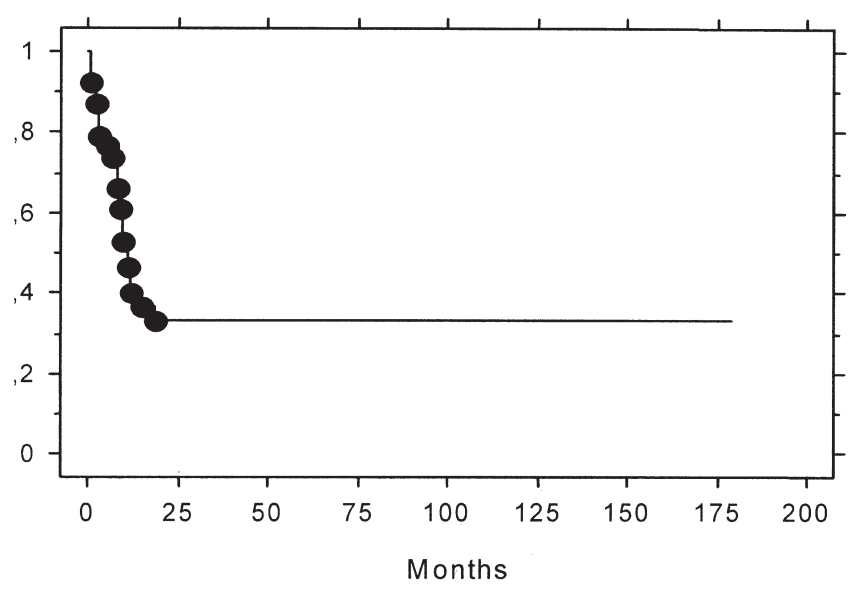

Figure 1. Overall survival.

Macroscopic analysis revealed that the tumors were poorly circumscribed and contained hemorrhagic foci. Necrosis was present in 35 (90\%) tumors, and blood vessel invasion was present in $9(23 \%)$ cases. According to histologic data (Table 1), 18 times the GCC component was predominant, and 21 times the SCC component was predominant.

Three patients died at 10,12 , and 28 postoperative days of myocardial infarction, hemothorax, and upper digestive hemorrhage, respectively. There were 4 major complications (empyema, pneumonia, hemothorax, and small bowel perforation) and 8 minor complications. The mean hospital stay was 12 days (range, 7-46 days). Seventeen patients had complementary treatments: chemotherapy was administered as induction therapy, adjuvant therapy, or both (alkylating agent [cisplatin] + antimetabolite [gemcitabine] or spindle poisons [vinorelbine or taxane]); radiotherapy was administered as adjuvant therapy.

Median follow-up was 24 months (range, 1-179 months). Fifteen patients are still alive, but 3 had metastatic recurrences (brain, small bowel, and lung, respectively) managed by means of surgical intervention and chemotherapy. Twenty-four patients have died. Except for the 3 patients who died in the immediate postoperative period, the others all died of recurrent disease: local (10 cases), metastatic (brain in 9, bone in 6, lung in 4, bowel in 2, and suprarenal gland in 1), or both. The mean DFI was 4 months (range, 2-19 months).

The overall 5-year survival rate was 33\% (median, 11 months; Figure 1); it was poorer for tumors of $7 \mathrm{~cm}$ or larger $(7.5 \%)$ than for tumors of less than $7 \mathrm{~cm}(56 \% ; P=.0026$; Figure 2). Twenty-four patients relapsed. The 5-year survival rate was also poorer when the DFI was less than 6 months $(0 \%$; 18 patients) than when it was 6 months or longer (33\%; 6 patients; $P=.0019$; Figure 3 ).

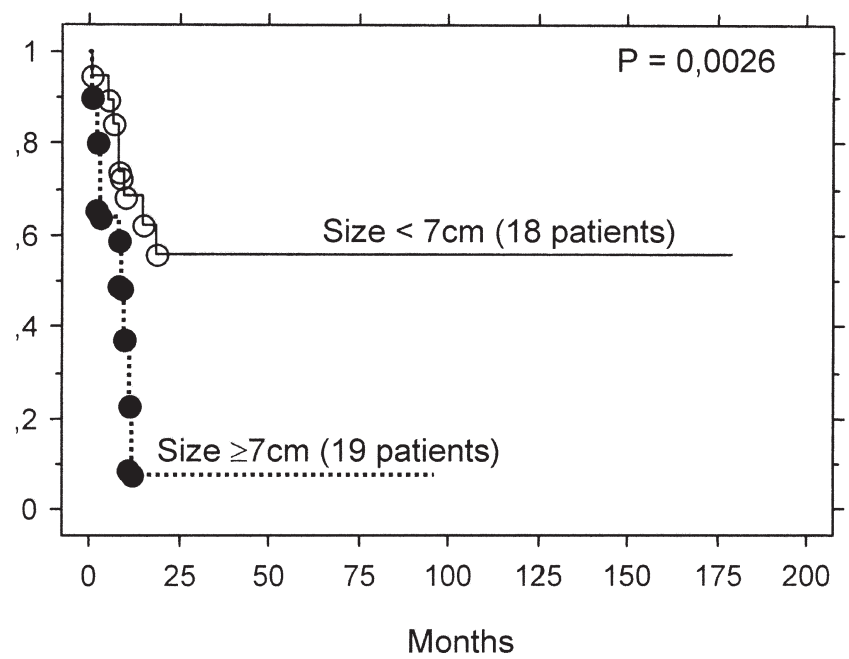

Figure 2. Overall survival according to tumor size.

Nonsignificant differences were noted for histology (49\% GCC predominant vs $21 \%$ SCC predominant, $P=$ $.08)$, complementary treatments (51\% with vs $21 \%$ without, $P=.06$ ), lymph node involvement (36\% for N0 vs $24 \%$ for N1/N2, $P=.21$ ), and stage of disease ( $48 \%$ for stage I vs $29 \%$ for stage II/III, $P=.71$ ). Multivariate analysis showed that DFI was the only factor predictive of a poor prognosis $(P=.0126)$.

\section{Discussion}

Also known as biphasic carcinomas, SCSGCs are rare tumors, accounting for only $0.3 \%$ to $1.3 \%$ of all lung tumors. ${ }^{6,8,12-14,18}$ In our experience they represent $1.4 \%$. However, this percentage might be underestimated because

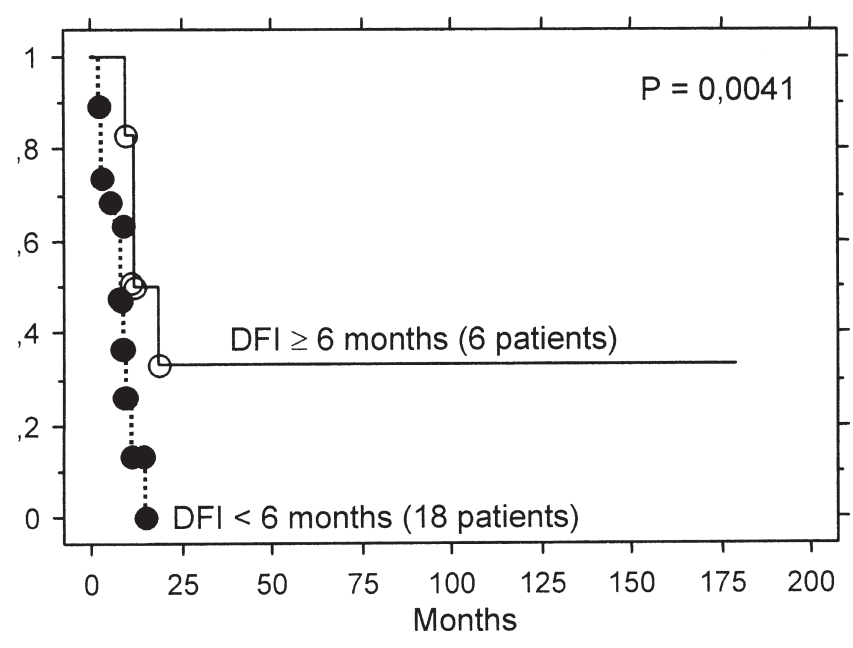

Figure 3. Overall survival according to the disease-free interval (DFI). 
Table 2. Reported series for sarcomatoid lung cancer (spindle/giant cells)

\begin{tabular}{|c|c|c|c|c|}
\hline Reference & $\begin{array}{l}\text { No. of patients (period of } \\
\text { study [y]/centers) }\end{array}$ & 5-y survival & Median survival (mo) & Prognostic factors \\
\hline Ishida and coworkers ${ }^{12}$ (1990) & $8(13 / 2)$ & - & 8 & - \\
\hline Ro and coworkers ${ }^{11}$ (1992) & $14(31 / 1)$ & - & 13 & - \\
\hline Ginsberg and coworkers ${ }^{15}$ (1992) & $16(12 / 1)$ & - & 14 & - \\
\hline Fishback and coworkers ${ }^{13}$ (1994) & $57^{*}(20 / 1)$ & $10 \%$ & 10 & Stage I, N0, size \\
\hline Attanoos and coworkers ${ }^{9}$ (1998) & $46(12 / 2)$ & $15 \%$ & 18 & - \\
\hline Nakajima and coworkers ${ }^{8}$ (1999) & $37(18 / 2)$ & - & - & Stage I, NO \\
\hline Chang and coworkers ${ }^{16}(2001)$ & $7 \dagger(10 / 1)$ & - & 5 & - \\
\hline Rossi and coworkers ${ }^{6}$ (2003) & $71 \ddagger(17 / 2)$ & - & 19 & Stage I \\
\hline Pelosi and coworkers ${ }^{7}$ (2003) & $31(11 / 2)$ & - & - & Stage I \\
\hline Raveglia and coworkers ${ }^{14}$ (2004) & $20(4 / 1)$ & - & 8 & Stage I, NO \\
\hline Our series (2006) & $39(15 / 1)$ & $33 \%$ & 11 & Size, DFI \\
\hline
\end{tabular}

Centers, Number of participating institutions; $N$, lymph node involvement; $D F I$, disease-free interval. *Seventy-eight patients/57 patients treated with surgical intervention. †Sixteen patients/7 patients treated with surgical intervention. ¥Seventy-five sarcomatoid cancers/71 spindle/giant cells cancers.

the classification has changed over time. The 1981 WHO classification placed tumors with a giant cell component in the group of large cell carcinomas and classed tumors with a spindle cell component in the group of squamous cell carcinomas. ${ }^{3}$ Since the 1990s, this particular type of tumor has received increased attention, ${ }^{7,9-13,15}$ and the most recent WHO classification groups them together. ${ }^{4,5}$

Histologic identification of these tumors remains difficult and requires examination of the resected surgical specimen for several reasons.

First, SCSGCs are a highly heterogeneous group of tumors. In addition to the sarcomatous component, we encountered all other types of carcinomas in our series: 13 adenocarcinomas, 13 squamous cell carcinomas, and 9 large cell carcinomas. Moreover, 12 of the tumors contained a mixture of 3 cell types.

Second, the most recent WHO classification, published in $1999^{4}$ and revised in $2004,{ }^{5}$ requires a minimum sarcomatoid component of $10 \%$ for positive diagnosis. In light of this mixed multicellularity and the variations in the percentages of the cell types, no preoperative technique permits accurate tumor diagnosis. Despite positive proof of cancer in 19 of our patients, only 1 examination oriented the diagnosis.

Finally, it is not known which component has a metastatic potential. For example, the prevalent brain lesion in our M1 patient consisted solely of adenocarcinoma, whereas the lung tumor had 3 components: $30 \%$ GCC, a predominance of adenocarcinoma, and large cell carcinoma.

Our retrospective study also investigated the clinical and prognostic behavior. Comparison of $\mathrm{CT}$ and pathologic findings ${ }^{19,20}$ revealed that an SCSGC should be suspected for any peripheral necrotic lesion surrounded by groundglass attenuation. No study has been published in the international literature on the use of F-18 FDG-PET scans. Fourteen patients in our study benefited from this imaging modality, and all of their tumors showed intense enhancement (standardized uptake value range, 16-26), a sign of potential aggressiveness. ${ }^{21}$

The estimated 5-year survival rate in surgical series varies between $13 \%$ and $21 \% .^{6-9,13-16}$ In our study 5-year survival was $33 \%$. Even if the 3 postoperative deaths are excluded, the gain in survival was minimal ( $36 \%$ at 5 years). Naruke and colleagues ${ }^{22}$ reported the following 5-year survival rates for other types of NSCLCs after surgical intervention: adenocarcinoma, 44\%; squamous cell carcinoma, 43\%; and large cell carcinoma, 38\%. There are several possible explanations for this poor prognosis.

First, limited stages like IB or IIB had poorer 5-year survival rates than other types of cancer: $48 \%$ and $21 \%$ in our study and $62 \%$ and $40 \%$ for adenocarcinoma, $58 \%$ and $49 \%$ for squamous carcinoma, and $54 \%$ and $38 \%$ for large cell carcinoma, respectively. ${ }^{22}$

Second, analysis of the natural history of the tumors in our patients revealed several interesting features: there were no small $\mathrm{T} 1$ tumors, and $72 \%$ of our patients had N0 disease. Recurrences were mostly distant hematogeneous rather than local lymph node metastases, and they were observed after a mean DFI of 4 months. All but 3 of our patients died after a mean survival of 8 months. The DFI was correlated with survival. Patients who relapsed with a DFI of less than 6 months had a 1-year survival rate of only $8.3 \%$, and all of them had died at 15 months. The 3 living patients (with recurrences) all had a DFI of 6 months or longer. The short mean DFI highlights the value of F-18 FDG-PET scans for the detection of metastatic disease.

Third, the majority of events happened during the first year. The 1-year survival rate was only $40 \%$. All of our patients who passed the 2-year barrier are considered longterm survivors.

Although survival is somewhat better when complementary treatments are administered, the difference is not sta- 
tistically significant, perhaps because of several limitations: retrospective study, small number of patients, or even the biphasic features of SCSGC. Currently, all treatment strategies and prognostic behaviors are based on monophasic tumor types.

In our experience the only prognostic factor was tumor size. Other authors have reported similar findings (Table 2). ${ }^{6-9,11-15}$ Interestingly, our patient with M1 pT2 N0 disease had the longest survival (almost 180 months). She had 2 recurrences, 19 months (small bowel metastasis) and 30 months (suprarenal metastasis) after lung surgery, respectively. Each time, management consisted of surgical intervention and adjuvant chemotherapy.

From a pragmatic point of view, the clinical features and survival data reflect tumor aggressiveness. Most of our patients relapsed and died within 12 months of surgical intervention. Thereafter, the small-stage 5-year survival rate was slightly shorter than that of other types of NSCLCs. Long-term survival can sometimes be achieved by means of lung resection combined with complete lymph node dissection. Complementary treatments had no significant value in our study, perhaps because of these tumors' biphasic composition. Induction or adjuvant chemotherapy should be considered when the diagnosis is suspected preoperatively because of the aggressive behavior of these tumors.

\section{References}

1. Remontet L, Esteve J, Bouvier AM, Grosclaude P, Launoy G, Menegoz F, et al. Cancer incidence and mortality in France over the period 1978-2000. Rev Epidemiol Sante Publique. 2003;51:3-30.

2. Sant M, Aareleid T, Berrino F, Bielska Lasota M, Carli PM, et al. EUROCARE Working Group. EUROCARE-3: survival of cancer patients diagnosed 1990-94-results and commentary. Ann Oncol. 2003;14(suppl 5):v61-118.

3. Sobin LH, editor. Histological typing of lung tumors. 2nd ed. Geneva: World Health Organization; 1981.

4. Travis WD, editor. Histological typing of lung tumors and pleural tumors. 3rd ed. Geneva: World Health Organization; 1999.

5. Travis WD. World Health Organization classification of tumors. Pathology and genetics of tumors of the lung, pleura, thymus and heart. 4th ed. Geneva: World Health Organization; 2004.

6. Rossi G, Cavazza A, Sturm N, Migaldi M, Facciolongo N, Longo L, et al. Pulmonary carcinomas with pleomorphic, sarcomatoid or sarco- matous elements: a clinicopathologic and immunohistochemical study in 75 cases. Am J Surg Pathol. 2003;27:311-24.

7. Pelosi G, Fraggetta F, Nappi O, Pastorino U, Maisonneuve P, Pasini F, et al. Pleomorphic carcinomas of the lung show a selective distribution of gene products involved in cell differentiation, cell cycle control, tumor growth, and tumor cell motility. Am J Surg Pathol. 2003;27: 1203-15.

8. Nakajima M, Kasai T, Hashimoto H, Iwata Y, Manabe H. Sarcomatoid carcinoma of the lung: a clinicopathologic study of 37 cases. Cancer. 1999;86:608-16.

9. Attanoos RL, Papagiannis A, Suttinart P, Goddard H, Papotti M, Gibbs AR. Pulmonary giant cell carcinoma: pathological entity or morphological phenotype? Histopathology. 1998;32:225-31.

10. Wick MR, Ritter JH, Humphrey PA. Sarcomatoid carcinomas of the lung: a clinicopathologic review. Am J Clin Pathol. 1997;108:40-53.

11. Ro JY, Chen JL, Lee JS, Sahin AA, Ordonez NG, Ayala AG. Sarcomatoid carcinoma of the lung. Immunohistochemical and ultrastructural studies of 14 cases. Cancer. 1992;69:376-86.

12. Ishida T, Tateishi M, Kaneko S, Yano T, Mitsudomi T, Sugimachi K, et al. Carcinosarcoma and spindle cell carcinoma of the lung: clinicopathologic and immunohistochemical studies. J Thorac Cardiovasc Surg. 1990;100:844-52.

13. Fishback NF, Travis WD, Moran CA, Guinee DG Jr, McCarthy WF, Koss MN. Pleomorphic (spindle/giant cell) carcinoma of the lung. Cancer. 1994;73:2936-45.

14. Raveglia F, Mezzetti M, Panigalli T, Furia S, Giuliani L, Conforti S, et al. Personal experience in surgical management of pulmonary pleomorphic carcinoma. Ann Thorac Surg. 2004;78:1742-7.

15. Ginsberg SS, Buzaid AC, Stern H, Carter D. Giant cell carcinoma of the lung. Cancer. 1992;70:606-10.

16. Chang YL, Lee YC, Shih JY, Wu CT. Pulmonary pleomorphic (spindle) cell carcinoma: peculiar clinicopathologic manifestations different from ordinary non-small cell carcinoma. Lung Cancer. 2001;34:91-7.

17. Mountain CF. Revisions in the International System for Staging Lung Cancer. Chest. 1997;111:1710-7.

18. Travis WD, Travis LB, Devesa SS. Lung cancer. Cancer. 1995;75: 191-202.

19. Kim TS, Han J, Lee KS, Jeong YJ, Kwak SH, Byun HS, et al. CT findings of surgically resected pleomorphic carcinoma of the lung in 30 patients. AJR Am J Roentgenol. 2005;185:120-5.

20. Kim TH, Kim SJ, Ryu YH, Lee HJ, Goo JM, Im JG, et al. Pleomorphic carcinoma of lung: comparison of CT features and pathologic findings. Radiology. 2004;232:554-9.

21. Cerfolio RJ, Bryant AS, Ohja B, Bartolucci AA. The maximum standardized uptake values on positron emission tomography of a non-small cell lung cancer predict stage, recurrence, and survival. J Thorac Cardiovasc Surg. 2005;130:151-9.

22. Naruke T, Tsuchiya R, Kondo H, Asamura H. Prognosis and survival after resection for bronchogenic carcinoma based on the 1997 TNMstaging classification: the Japanese experience. Ann Thorac Surg. 2001;71:1759-64. 